\title{
Cognitive therapy for the treatment of delusions
}

\section{Douglas Turkington \& Ronald Siddle}

Traditionally, delusions have been viewed as false, unshakeable beliefs which arise out of internal morbid processes and are out of keeping with a person's educational and cultural background (Hamilton, 1978). Primary delusions appear to arise without understandable cause, and secondary delusions appear more understandable in relation to the prevailing affective state or cultural climate (Sims, 1995), for example. However, during the cognitive therapy process we would expect that even primary delusions might become more understandable as the patient's life history and belief profile are gradually disclosed.

Roberts (1991) describes some primary delusions as being potentially adaptive, leading to protection from depression and to an enhanced sense of meaning. Also, Harrow et al (1988) estimate that 70\% of delusional ideas relate to non-delusional beliefs that pre-date the delusion. Delusions are, according to a number of researchers, points along a continuum with overvalued ideas and normal beliefs (Strauss, 1969; Chapman \& Chapman, 1988; Jones \& Watson, 1997). This continuum hypothesis, along with other research postulating that delusions are a reflection of a defensive attributional style protecting against low self-esteem (Lyon et al, 1994), provides the theoretical basis for many of the techniques and approaches used in the cognitive therapy of delusions.

Cognitive therapy is a psychological treatment used nowadays in the majority of psychiatric disorders with differing levels of proven efficacy. It is active, directive, time-limited, structured and collaborative (Becket al, 1979). Some time ago, there was a wider divide between cognitive therapy and cognitive-behavioural therapy. Cognitive therapy having a more cognitive focus, and being much more formulation driven, and focused on schema change, while cognitive-behavioural therapy was traditionally more behaviourally oriented. Now the position is much less clear, with the terms cognitive therapy and cognitive-behavioural therapy being used more or less synonymously; in this paper, the terms cognitive therapy and cognitive-behavioural therapy refer to the same therapeutic stance and range of techniques.

Most of the research on cognitive therapy so far has been done on depression. Cognitive therapy has been shown to be effective in both endogenous and non-endogenous depression (Blackburnet al, 1981) and also has a value in relapse prevention (Evanset $a l, 1992)$. Its efficacy in anxiety disorders (Blackburn \& Davison, 1990) is relatively well known. Recent, randomised controlled trials which have been evaluating cognitive therapy in the treatment of schizophrenia are coming to fruition (Kuiperset al, 1997) to support an early promising but uncontrolled study (Kingdon \& Turkington, 1991) indicating the potential benefits to be gained from this method of treating schizophrenia. The cognitive therapy approach to schizophrenia is much broader, including components directed towards coping skills (Tarrier et al, 1993), medication compliance (Kemp et al, 1996) and negative symptoms (Hogg, 1996). Delusions as treated within schizophrenia are tackled within this broader framework and techniques integrated within the overall direction of therapy (Fowler et al, 1995). In this situation one of the key predictors of response is cognitive flexibility concerning delusions (Garety et al, 1997). Huq et al (1988) have shown that deluded patients require less information and controls on probabilistic reasoning tasks and express greater certainty over their judgements; that is, deluded patients tend not

Douglas Turkington is a consultant psychiatrist at St Nicholas Hospital, Jubilee Road, Gosforth, Newcastle upon Tyne NE3 3XT and a cognitive therapist specialising in cognitive therapy with psychotic disorders. Ronald Siddle is a research fellow at the University of Manchester and an accredited cognitive therapist working in the Socrates Study investigating cognitivebehavioural therapy in early schizophrenia. 
to take into account the available evidence, jump to conclusions and then hold their conclusion with greater certainty. This research would seem to hint that a cognitive therapy approach towards delusions, which involves collecting and re-examining the evidence and generating hypotheses, would seem to be of potential benefit. It would also point towards the benefits of cognitive remediation (Brenner $e t$ al, 1990) in improving attentional deficits and other neuropsychological deficits which are often present in schizophrenia and which hinder such realitytesting work. This paper takes a narrower focus on specific techniques as applied to delusions and their impact on the patient's affect and behaviour.

\section{Historical development}

Given that delusions are defined as unshakeable, there would seem little point in attempting to use valuable resources on such lost causes, regardless of progress made in people with schizophrenia. However, there are one or two investigations which suggest the contrary; that delusions can be held with varying degrees of belief, and are amenable to appropriate methods of treatment (see Box 1). Hemsley \& Garety (1986) showed two factors to be pertinent to the development and maintenance of abnormal beliefs. They were, expectation and current relevant environmental information. These are the same factors which mediate the development of normal beliefs which, like delusions, are also highly resistant to change with a tendency to disregard contradictory information. Perhaps delusions are not categorically different from normal beliefs. Beck (1952) provided an early case example of the use of what is now called cognitive therapy in the case of a man with a long history of a systematised persecutory delusional system. This delusion was completely given up, mostly using a questioning and reality-testing approach. Beck's work suggested that delusions might be modifiable by appropriate methods, and a number of small-scale studies provide some support for this. Wattset al (1973), Hole et al (1979), Lowe \& Chadwick (1990) and Turkington et al (1996) using small sample sizes confirmed these findings, and did so using only six or eight sessions of therapy. Milton et al (1978) concluded that the most effective style of therapy was to attempt to modify beliefs collaboratively rather than by adopting a confrontational style. Though these papers support the role for a cognitive therapy approach to delusional ideas, it must be said that this assertion has not yet been effectively tested using appropriate methodology concentrating specifically on delusions alone.
Box 1. Pioneers of cognitive therapy for delusions

Beck, 1952 Many of the techniques outlined

Milton et al, Belief modification 1978

Lyon et al, 1994 Delusions providing a protective function for self esteem

Roberts, 1991 Adaptive function of delusions

Hemsley \& Reasoning processes Garety, 1986

Chadwick \& Measurement and Lowe, 1990 modification

Kingdon \& Cognitive-behavioural

Turkington, therapy in schizophrenic 1991 delusions

Turkington et al, Redefinition of delusion 1996

\section{Measures of change}

Cognitive therapy is a scientific psychotherapy, which relies on a focused approach with a measurable outcome. Attempts to measure delusions have provided a wealth of models and scales (Chadwick \& Lowe, 1990, 1994; Buchanan et al, 1993; Wessely et al, 1993), of which none has really been widely accepted as providing a 'gold standard' against which others can be validated. Of these, the Maudsley Assessment of Delusions Schedule (MADS) described by Buchananet al (1993) is one of the most comprehensive. This measure offers a reliable semi-structured interview, with sensitivity and face validity, though it is somewhat cumbersome and lacking in its ability to offer a simple scoring system for severity.

In practice it is often difficult to separate clinical assessment from treatment (Alford \& Beck, 1994), an assertion supported by Hole et al (1979) whose attempt at merely the measurement of delusional ideas by interview produced surprising reductions in conviction ratings. Because of the idiosyncratic nature of delusions Alford \& Beck (1994) suggest individualised rather than nomothetic assessment procedures, focusing upon frequency of related behaviour, conviction and emotions which accompany delusions. 
Harrow et al (1988) propose three basic dimensions to a delusional idea. These are: belief conviction; the patient's awareness of how others will view his delusional ideas; and the immediacy or urgency which the patient attaches to the delusional idea. Others such as Kendler et al (1983) propose five dimensions to their measurement of delusions. These researchers' proposed dimensions are: conviction; the degree to which the belief extends into other aspects of life; bizarreness; disorganisation; and pressure (or preoccupation).

Of these various dimensions of delusions, belief of the conviction appears in all. Belief conviction is recognised by some (Hole et al, 1979) to be the principal aspect to delusional ideation and seems also the simplest to quantify.

Other simple measures of delusions may be of more use to psychiatrists in practice. Examples of these will include patients stopping or reducing their thinking about (or acting upon) their delusions (decreased pervasiveness), beginning to doubt the validity of their delusions (decreased conviction) or both of these. Given that most psychiatrists in clinical practice have not got the time to conduct comprehensive assessments or semi-structured interviews of delusional ideas, these simpler measures may be adequate for most instances.

\section{Process of therapy}

\section{Assessment}

Like all other beliefs within the normal population, belief change can only be gradually attempted once the exact belief and its emotional and behavioural sequelae are articulated. At no time during the assessment phase would a contradiction or challenge be made. The origins of the belief in terms of chronology and pre-existing beliefs should be explored. The conviction with which the belief was held and the possibility of alternative explanations should be stated. Emotional reactions to the belief, such as anger, anxiety or sadness, should be discovered, along with any positive (e.g. searching or aggression) or negative (e.g. avoidance or withdrawal) behaviours. The potential importance of the belief should be considered in relation to selfesteem. The MADS (Buchanan et al, 1993) may be used to assess progress in any delusional parameter.

\section{Therapeutic alliance}

In dealing with delusions an atmosphere of collaborative empiricism should be maintained at all times if possible. It will often feel as if the patient with the delusion is attempting to draw the therapist in to a confrontational stance. It seems very important to avoid this by using responses such as: "well, that is a possible explanation, but could it be anything else?" or "let's explore the evidence and see if your ideas are right".

The attitude in such sessions is of being two research workers looking for the evidence to test out one hypothesis after the other to see which is the best fit. The tightrope which the cognitive therapist has to walk is that of asking questions of appropriate depth and pace while maintaining an attitude of non-confrontation and non-collusion (see Box 2).

\section{Techniques}

\section{Peripheral questioning}

This involves asking questions of fact of the delusional belief, for example: "how might something like that work?" Such questions do not threaten the core of the delusion and normally maintain collaboration without threatening selfesteem. As such, these questions are used most often in early sessions and lead directly to reality-testing homework. A patient who believes himself to be the subject of persecution, for example, will probably never have systematically checked out the balance of evidence in relation to this.

\section{Socratic questioning}

A train of questions based on implication, which would tend to lead the deluded patient to an entirely different conclusion, is given below:

Patient: "I am the Queen of Spain."

Therapist: "Let's presume for a minute that this belief is completely true and let's look at some of the implications."

Therefore:

Therapist: "There must have been a coronation. When might that have happened?"

Therapist: "You must be able to speak in excellent Spanish. Perhaps you could teach me some useful phrases?"

Therapist: "Are there many state visits to other countries? Which countries have you visited?"

This is a much more penetrating and challenging form of questioning which would only be attempted later in cognitive therapy when the patient was beginning to be doubtful of their beliefs. Questioning such as this must always be deployed with sensitivity to the patient's emotional 
state and with empathy to the possible consequences of belief change.

\section{Inference chaining}

The purpose here is to work beneath the delusion, in particular grandiose or systematised delusions, which are often resistant to other techniques because of their protective function in relation to self-esteem. This should be delayed until later stages, or where other techniques are inappropriate; for example:

Patient: "I am the Queen of Spain."

Therapist: "What does this mean to you to hold this belief?"

Patient: "It means that I am admired by everyone."

Therapist: "What does this mean to you to be admired by everyone?"

Patient: "It means that I will not have to take abuse from anyone anymore" (tears because of reaching a 'hot cognition').

Therapist: "What would that mean to you, to suffer no more abuse?"

Patient: "I just want to be my normal self, without criticism" (further tears).

A 'hot cognition' is a cognition which carries with it a powerful affective change indicating an important arena for further intervention.

\section{Schema focused work}

Clearly, in the example above, the work at the schema level would focus on issues of approval demands and underlying low self-esteem. Schemas include core maladaptive beliefs, for example: "I am unlovable" and compensatory beliefs such as: "I must be approved of at all costs". These are strongly held beliefs about the self which are typically not challenged and often the patient is not even aware of them. Schemas can be detected from following the general themes in cognitions, from questioning the meaning of specific events and from inferencechaining to detect hot cognitions. Techniques involve

Box 2. Techniques

Collaborative empiricism

Peripheral questioning

Reality-testing

Socratic questioning

Inference chaining

Schema level work articulating the evidence, positive and negative logging of approvals, acting against the belief in imagery and in real-life situations, and direct disputation.

\section{Case study}

\section{The Godfather}

David was a 57-year-old man who was admitted to hospital under Section 3 of the Mental Health Act 1983 when he was 51 years old. He reported more than 20 years of surveillance and persecution by the Mafia. This was ushered in by an episode of delusional perception within months of him losing his job as an accountant. At the time of admission he said that he had suffered enough, he had been intending to travel to London to drown himself in the Thames. Negative symptoms were also present, including emotional blunting, reduced self-care and reduced drive. He had previously been admitted on three occasions informally but had always refused neuroleptics or any other form of treatment. He believed that he was the victim of persistent surveillance with cars doing U-turns when he approached or flashing their lights to each other to indicate his presence (delusions of reference). He had previously made an arson attempt on his mother's house and had stabbed an 85-yearold neighbour, believing her to be a co-conspirator. There was a family history of schizophrenia, ending in suicide, but this was very much held as a family secret.

His personal history included bisexual orientation but no current sexual activity. He lived in a run-down inner-city area in a setting of increased social isolation, as he had gradually alienated all family members and friends. He was open about the surveillance and persecution and engaged well in the cognitive therapy sessions without excessive distress. Assessment revealed the extent of his persecutory and surveillance delusions and his emotional and behavioural responses. Secondary delusions were expressed, including his belief that he had been adopted and was actually the son of a Mafia 'godfather'. Exploration of his delusional perception revealed that, at a time of great distress and despair, he had developed a delusional mood then, on seeing a limousine drive past, the realisation dawned upon him that he was 'special' and under surveillance. He could initially see no link between the stress of losing his job and status in life and the development of these symptoms.

The cognitive model was then explained to him, using de-centering vignettes (demonstrations of other people's inappropriate thinking as in, for example, road rage and public speaking anxiety situations) and the patient was taught to weigh the evidence and use rational responses for 
dysfunctional thoughts in situations, leading to emotional and behavioural change. Working through the antecedents of the emergence of psychotic symptoms did not, on this occasion, lead to any improvement in understanding, but this can be a very illuminating experience for patient and therapist. Peripheral questions were used gently to probe for information around the edges of the delusion in relation to factual knowledge about surveillance techniques and resource implications. Percentage belief allocation was made to the delusional belief and a number of other alternative options with a view to homework exercises designed to test out these options. At no time was there any direct confrontation of the delusional content. Initial homework was to check out the delusions of reference by looking for cars doing U-turns and flashing their lights. When the evidence was directly considered in this way with the help of one of the in-patient nurses, he was puzzled to find that such phenomena were infrequent and that most could be easily explained. On exploring in more detail the facial expressions, clothes and behaviour of alleged persecutors, he was able to discard some of them as being people behaving normally. After several such reality-testing episodes, the percentage belief allocation in the Mafia started to fall. He also, for the first time, agreed to take sulpiride $200 \mathrm{mg}$ three times a day. It seemed that the interest and respect given to his beliefs was rewarded by improved compliance, mostly based on the rationale that the medication would help to "calm the system down" and aid 'clarity of thinking'.

Inference-chaining revealed an underlying dysfunctional assumption of a need to be special, compensating for underlying schemas of abandonment and unlovability. As his delusions started to recede, he developed a depressive state and was described by nursing staff as being 'like a man in a vacuum', so little meaning did his life appear to have. The depression improved with a schema-focused approach. Relatives were contacted and photographic albums brought in of his early family life. His father had been away fighting at war and David had laid down schemas of being unloved and abandoned. He then misunderstood certain comments by key relatives in such a way as to believe that there was something special or different about him. He linked this to the fact that Italian prisoners of war were being kept on the family farm. Eventually he was able to 'make sense of it all'. The depression improved on realising his own true place in his family and of his father's true feelings for him. Follow-up after six years has revealed no further evidence of his delusions, and a gradual moderate improvement in negative symptomatology.
This case is interesting in that both the form of the symptomatology and the content became understandable within the course of cognitive therapy. Compliance with medication was also improved by this way of collaboratively tackling symptomatology, and the emergence of a depression seemed to cure this self-esteem-maintaining delusion. The issue of which is the effective element in recovery remains to be clarified. However, if the improvement was achieved largely through an effect on improved medication compliance, this would be just as acceptable as a recovery which is achieved by psychological means alone.

\section{Conclusions}

We conclude that all available evidence points towards the fact that delusions, at least in certain of their parameters, can be expected to shift along the spectrum towards normality when a cognitive therapy approach is used. It is unclear at present whether the effect is a general one due to the nonconfrontational therapy style or whether it is due to specific techniques or an effect on improved medication compliance. We would advocate the use of the techniques described in out-patient settings and in the community, whenever a deluded patient is being treated. Full therapy, as described, should be undertaken in a setting of supervision and in a situation where there is adequate time for 45-minute weekly sessions, and a keyworker in the community who can help with homework experiments. Obviously, scarce resources should only be allocated to such a therapy task when an assessment supports the time expenditure required and where the entire treatment team is supportive of the cognitive therapy approach. The approach is very well suited to acute psychiatric in-patient units (Drury et al, 1996) where a team cognitive therapy approach can often help delusions not to become entrenched. We believe that the development of this approach would be facilitated by the teaching of a less categorical description of delusion than the one currently taught. We recommend that the definition of delusion be revised as follows:

"A delusion is a false belief at the extreme end of the continuum of consensual agreement. It is not categorically different to overvalued ideas and normal beliefs. It is held in spite of evidence to the contrary but it may be amenable to change when that evidence is collaboratively explored. In that case, the belief may come to approximate more closely to ideas in keeping with the patient's social, educational, cultural and religious background" (Turkington et al, 1996). 


\section{References}

Alford, B. A. \& Beck, A. T. (1994) Cognitive therapy of delusional beliefs. Behaviour Research and Therapy, 32 369-380.

Beck, A. T. (1952) Successful out-patient psychotherapy of a chronic schizophrenic with a delusion based on borrowed guilt. Psychiatry, 15, 305-312.

-, Rush, A. J., Shaw, B. F., et al (1979) Cognitive Therapy of Depression. Guilford: New York.

Blackburn, I. M. \& Davidson, K. (1990) Cognitive Therapy for Depression and Anxiety. Oxford: Blackwell.

-, Bishop, S., Glen, A. I. M., et al (1981) The efficacy of cognitive therapy in depression: a treatment trial using cognitive therapy and pharmacotherapy, each alone and in combination. British Journal of Psychiatry, 139, 181-189.

Brenner, H. D., Hodel, B. \& Roper, V. (1990) Integrated cognitive and behavioural interventions in the treatment of schizophrenia. Psychosocial Rehabilitation Journal, 13, 41-43.

Buchanan, A., Reed, A., Wessely, S., et al (1993) Acting on delusions. II: The phenomenological correlates of acting on delusions. British Journal of Psychiatry, 163, 77-81.

Chadwick, P. D. J. \& Lowe, C. F. (1990) Measurement and modification of delusional beliefs. Journal of Consulting and Clinical Psychology, 58, 225-232.

— \& - (1994) A cognitive approach to measuring and modifying delusions. Behaviour Research and Therapy, 32, 355-367.

Chapman, L. J. \& Chapman, J. P. (1988) The genesis of delusions. In Delusional Beliefs (eds F. Oltmanns \& B. A. Maher), pp. 167183. New York: Wiley.

Drury, V., Birchwood, M., Cochrane, R., et al (1996) Cognitive therapy and recovery from acute psychosis: a controlled trial. I. Impact on psychotic symptoms. British Joumal of Psychiatry, 169, 593-601.

Evans, M. D., Hollon, S. D., DeRubeis, R. J.,et al (1992) Differential relapse following cognitive therapy and pharmacotherapy for depression. Archives of General Psychiatry, 49, 802-808.

Fowler, D., Garety, P. A. \& Kuipers,E. (1995) Cognitive Behaviour Therapy for People with Psychosis: A Clinical Handbook. Chichester: Wiley.

Garety, P. A., Fowler, D., Kuipers, E., et al (1997) LondonEast Anglia randomised controlled trial of cognitivebehavioural therapy for psychosis. II: Predictors of outcome. British Journal of Psychiatry, 171, 420-426.

Hamilton, M (1978) Fish's Outline of Psychiatry (3rd edn). Bristol: John Wright.

Harrow, M., Rattenbury, F. \& Stoll, F. (1988) Schizophrenic delusions: an analysis of their persistence, of related premorbid ideas, and of three major dimensions. In Delusional Beliefs (eds F. Oltmanns \& B. A. Maher), pp. 185-211. New York: John Wiley.

Hemsley, D. R. \& Garety, P. A. (1986) The formation and maintenance of delusions: a Bayesian analysis. British Journal of Psychiatry, 149, 51-56.

Hogg, L. (1996) Psychological treatments for negative symptoms. In Cognitive Behavioural Interventions With Psychotic Disorders (eds G. Haddock \& P. Slade), pp. 151167. London: Routledge.

Hole, R. W., Rush, A. J. \& Beck,A. T. (1979)A cognitive investigation of schizophrenic delusions. Psychiatry, 42, 312-319.

Huq, S. F., Garety, P. A. \& Hemsley, D. R. (1988) Probabilistic judgements in deluded and non-deluded subjects. Quarterly Journal of Experimental Psychology. A Human Experimental Psychology, 40, 801-812.

Jones, E. \& Watson, J. P. (1997) Delusion, the overvalued idea and religious beliefs: a comparative analysis of their characteristics. British Journal of Psychiatry, 170, 381-386.

Kemp, R., Hayward, P., Applewhaite, G.et al (1996) Compliance therapy in psychotic patients: randomised controlled trial British Medical Journal, 312, 345-349.

Kendler, K. S., Glazer, W. M. \& Morgenstern, H. (1983) Dimensions of delusional experience. American Journal of Psychiatry, 140, 466-469.
Kingdon, D. G. \& Turkington, D. (1991) The use of cognitive behaviour therapy with a normalising rationale in schizophrenia. Preliminary report. Journal of Nervous and Mental Diseases, 179, 207-211.

Kuipers, E., Garety, P. A., Fowler, D., et al (1997) LondonEast Anglia trial of cognitive-behavioural therapy for psychosis. I: Effects of the treatment phase. British Journal of Psychiatry, 171, 319-327.

Lowe, C. F. \& Chadwick, P. D. J. (1990) Verbal control of delusions. Behaviour Therapy, 21, 461-479.

Lyon, H. M., Kaney, S. \& Bentall, R. P. (1994) The defensive function of persecutory delusions: evidence from attribution tasks. British Journal of Psychiatry, 164, 637-646.

Milton, F., Patwa, K. \& Hafner, R. J. (1978) Confrontation $v$. belief modification in persistently deluded patients. British Journal of Medical Psychology, 51, 127-130.

Roberts, G. (1991) Delusional belief systems and meaning in life: a preferred reality? British Journal of Psychiatry, 159 (suppl. 14), 19-28.

Sims, A. (1995) Symptoms in the Mind. London: Sanders.

Strauss, J. S. (1969) Hallucinations and delusions as points on continua function. Archives of General Psychiatry, 21, 581-586.

Tarrier, N., Beckett, R., Harwood, S., et al (1993) A trial of two cognitive-behavioural methods of treating drug-resistant residual psychotic symptoms in schizophrenic patients: I. Outcome. British Journal of Psychiatry, 162, 524-532.

Turkington, D., John, C. H., Siddle, R.,et al (1996) Cognitive therapy in the treatment of drug-resistant delusional disorder. Clinical Psychology and Psychotherapy, 3, 118-128.

Watts, F. N., Powell, G. E. \& Austin, S. V. (1973) The modification of abnormal beliefs. British Journal of Medical Psychology, 46, 359-363.

Wessely, S., Buchanan, A., Reed, A., et al (1993) Acting on delusions. I: Prevalence. British Journal of Psychiatry, 163, 69-76.

\section{Mulitple choice questions}

1. Delusions are:

a categorical phenomena

b therapeutically inaccessible

c on a spectrum with overvalued ideas

d well dealt with by a distancing approach.

2. Cognitive therapy for delusions is appropriately described as:

a confrontational

b superficial

c reality-based

d antagonistic to pharmacological approaches.

3. Peripheral questions in relation to a delusion:

a may reduce linked distress

b are often seen as intrusive

c deal with matters of fact

d must be supervised.

4. Inference-chaining in relation to a delusion:

$a$ is used at the time of assessment

b must be done with caution

c can elicit painful emotions

$\mathrm{d}$ indicates underlying schemas. 
5. The following techniques make delusions entrenched:
a humouring
b distancing
c collusion
d confrontation.

\begin{tabular}{|cccccccccc|}
\hline \multicolumn{1}{|c|}{ MCQ answers } & & & & & & \\
$\mathbf{1}$ & 2 & & 3 & & 4 & & 5 & \\
a & F & a & F & a & T & a & F & a & T \\
b & F & b & F & b & F & b & T & b & T \\
c & T & c & T & c & T & c & T & c & T \\
d & F & d & F & d & F & d & T & d & T \\
\hline
\end{tabular}

\section{Commentary}

\section{Brian V. Martindale}

Turkington \& Siddle's article is written in a way that most helpfully allows comment from a range of perspectives; indeed, I was specifically invited to 'broaden its scope'. They clearly describe to readers the useful techniques by which cognitive therapy can diminish the power and domination of delusions in some patients with schizophrenia.

By presenting the reasonably detailed case history of the 'Godfather', a range of important issues are raised which would have been unavailable if we had been given only a statistical presentation on the treatment of delusions.

Turkington \& Siddle describe the traditional definition of delusions. However it is important to clarify that they are referring to the dominant tradition in British psychiatry. There are other traditions in Europe and in some places in Britain in which it has long been thought that delusions (and hallucinations) and other seemingly bizarre ideas and behaviours are the expression of highly meaningful individual issues. These are accessible if the clinician is familiar with both unconscious symbolisation and its disorders and unconscious mental mechanisms for dealing with unbearable feeling states (Jackson \& Williams, 1994; Lotterman, 1996). These understandings have led to the widespread implementation of a more integrated and sophisticated form of psychiatric practice with respect to psychotic disorders in some countries such as Finland (Alanen, 1997).

It is therefore particularly welcome that some practitioners of cognitive therapy, through their careful work with patients, are becoming increasingly appreciative of the personal dynamics of delusions and related phenomena. In the case of the Godfather it became clear to his cognitive therapists that becoming special and singled out was a defence against feelings of being a vacuous nobody, and that the trauma of being sacked from his work was also expressed in the feared attacks from the Mafia.

In the authors' discussion of technique, the establishment of a therapeutic alliance rightly receives a great deal of attention. On average it takes three years from the onset of frank illness and one year from the onset of overt psychosis before a person with schizophrenia finds his or her way to specialist help (Loebelet al, 1992). Having reached such services about $50 \%$ of people do not maintain contact with mental health services (Melzer et al, 1991). The Godfather had been psychotic for more than 20 years and had refused any form of treatment in the past. He was extremely alienated and isolated. Therefore, establishing and maintaining a relationship with him was the priority from which anything else would stem.

It seems that the very careful technique used allowed the therapeutic alliance gradually to 